\title{
Pechini synthesis of $\mathrm{Co}_{2} \mathrm{SiO}_{4}$ magnetic nanoparticles and its application in photo- degradation of azo dyes
}

\author{
Shima Bayat ${ }^{\text {a }}$, Davood Ghanbari ${ }^{\text {b }}$, Masoud Salavati-Niasari *a \\ ${ }^{a}$ Institute of Nano Science and Nano Technology, University of Kashan, Kashan, P.O. Box 8731753153, I. R. \\ Iran \\ ${ }^{b}$ Young Researchers and Elite Club, Arak Branch, Islamic Azad University, Arak, Iran \\ *Corresponding author: Tel.: +98315591 2383, Fax: +983155913201 ;E-mail address: \\ Salavati@kashanu.ac.ir
}

\begin{abstract}
In this work $\mathrm{Co}_{2} \mathrm{SiO}_{4}$ nanoparticles were synthesized via a facile Pechini sol-gel method. The prepared products were characterized by X-ray diffraction pattern (XRD), scanning electron microscopy (SEM), transmission electron microscopy (TEM), and Fourier transform infrared (FT-IR) spectroscopy. Alternating gradient force magnetometer (AGFM) illustrates para-magnetic behaviour of $\mathrm{Co}_{2} \mathrm{SiO}_{4}$ nanoparticles. The photocatalytic behaviour of $\mathrm{Co}_{2} \mathrm{SiO}_{4}$ nanoparticles was evaluated using the degradation of three azo dyes (acid black, acid brown and methyl orange) under ultraviolet light irradiation. The results show that nanocomposites have applicable magnetic and photocatalytic performance. In order to prepare polymeric nanocomposite, $\mathrm{Co}_{2} \mathrm{SiO}_{4}$ were added to poly styrene (PS) and polysulfone (PSu) matrices. Outcomes confirm that nanoparticles appropriately enhanced both thermal stability and flame retardant property of the PSu and PS matrices.

Keywords: Nano; Catalyst; Pechini; Composite.
\end{abstract}




\section{Introduction}

One of the less-studied olivine-type silicates is the synthetic $\mathrm{Co}_{2} \mathrm{SiO}_{4}$ that is widely used as a pigment in the ceramic industry, due to its stability at high temperatures. It has an orthorhombic structure, consists of a hexagonal closed-packed oxygen array in which half of the octahedral sites are occupied by cobalt atoms. It is currently being considered to be used as a magnetic material and a catalyst [1-3]. Many technological applications require materials with large surface area and small particle size. The most commonly used method for the preparation of mixed oxide pigments involves the calcination of the different oxides precursors at high temperatures. Attempts have been made to prepare $\mathrm{Co}_{2} \mathrm{SiO}_{4}$ using low temperature alternative methods to minimize the aggregation of the particles during the calcination. The magnetic and electronic properties of the $\mathrm{M}_{2} \mathrm{SiO}_{4}$ olivines (metal cations such as $\mathrm{Fe}, \mathrm{Co}$ and $\mathrm{Ni}$ ) have also been studied. $\mathrm{M}_{2} \mathrm{SiO}_{4}$ compounds crystallizing in the olivine structure are characterized by a distorted hexagonal close-packed array of oxygen anions in which one-eighth of the tetrahedral interstices are filled by silicon. A few works were reported for characterization on the structural, crystal-chemical, lattice dynamic, magnetic and thermodynamic properties of the olivine group of minerals [1-9].

Magnetic properties of nano-structures are very sensitive on the particle size and broad spectrum of magnetic properties has been obtained in the nanosized systems such as super para-magnetism, spin glass, high magnetization, high magnetic moment of the particles and high coercivity [9-10]. The demand for eliminating pollutants from water in order to provide safe water has urged innovating different purification procedures and among them, the photo-degradation reaction has attracted great attention. In these reactions, organic molecules mainly undergo decomposition reaction by interacting with a photo-catalyst material and UV or visible light to give $\mathrm{CO}_{2}$ and $\mathrm{H}_{2} \mathrm{O}$ as final products [9-13]. Nano-additives are very special due to the fact that adding of a small amount of nanostructure to a polymeric matrix can lead to improvement properties of the matrix. The principal profits of polymer matrices nanocomposites over many metallic alloys are corrosion resistance, low 
density and thermal insulation. However the main disadvantage of polymeric compounds is high flammability [13-16]. The special properties of magnetic nanoparticles including excellent chemical stability, suitable mechanical hardness, cost-effectiveness and possibility for precise control on the composition along with its ability to be separated by a magnet, has made them very attractive candidate to be used in nanocomposite photocatalysts [15-20]. The Pechini-type reaction was widely used to produce various morphologies of nanostructures such as nanorods, nanoplates and nanoparticles, its process is based on the ability of citric acid to chelate metallic ions which can undergo poly-esterification with polyhydroxyl alcohols such as ethylene glycol to form a polymeric precursor. In the present work $\mathrm{Co}_{2} \mathrm{SiO}_{4}$ nanocomposites were synthesized by a Pechini solgel method. [21-24]. The effect of capping agents on the morphology of the product was investigated in order to optimize the reaction condition for obtaining an efficient photocatalyst. For preparation of polymeric nanocomposite $\mathrm{Co}_{2} \mathrm{SiO}_{4}$ were added to poly styrene (PS) and poly sulfone (PSu) matrices. Outcomes confirm that nanoparticles appropriately enhanced both thermal stability and flame retardant property of the PSu and PS matrices.

\section{Experimental}

\subsection{Materials and methods}

$\mathrm{Co}\left(\mathrm{CH}_{3} \mathrm{COO}\right)_{2} 4 \mathrm{H}_{2} \mathrm{O}$, and tetra-ethyl ortho-silicate, citric acid, oxalic acid, maleic acid and succinic acid were purchased from Merck and all the chemicals were used as received without further purifications (Fig.1). Room temperature magnetic properties were investigated using an alternating gradient force magnetometer (AGFM and VSM) device, (Meghnatis Kavir Kashan Co., Kashan, Iran) in an applied magnetic field sweeping between \pm 10000 Oe. XRD patterns were recorded by a Philips, X-ray diffractometer using Ni-filtered $\mathrm{CuK}_{\alpha}$ radiation. SEM images were obtained using a LEO instrument model 1455VP. Prior to taking images, the samples were coated by a very thin layer of Pt (using a BAL-TEC SCD 005 sputter coater) to make the sample surface conductor and prevent charge accumulation, and obtaining a better contrast. A multiwave ultrasonic generator 
(Bandeline MS 73), equipped with a converter/transducer and titanium oscillator, operating at $20 \mathrm{kHz}$ with a maximum power output of $150 \mathrm{~W}$ was used for the ultrasonic irradiation.

\subsection{Synthesis of $\mathrm{Co}_{2} \mathrm{SiO}_{4}$ nanoparticles}

$\mathrm{Co}\left(\mathrm{CH}_{3} \mathrm{COO}\right)_{2} 4 \mathrm{H}_{2} \mathrm{O}(0.002 \mathrm{~mol})$, tetra-ethyl ortho-silicate $(0.001 \mathrm{~mol})$ and citric acid (or other capping agent) were stirred in solvent of ethylene glycol. The $\mathrm{pH}$ was adjusted to 8 by ammonia solution. The solution was stirred for $48 \mathrm{~h}$ by various capping agents. The precipitate was then centrifuged and rinsed with distilled water. The obtained precipitate was left to dry at $70{ }^{\circ} \mathrm{C}$. For preparation of $\mathrm{Co}_{2} \mathrm{SiO}_{4}$ the product was calcined at $700{ }^{\circ} \mathrm{C}$ for $5 \mathrm{~h}$. A black precipitate was obtained confirming the synthesis of $\mathrm{Co}_{2} \mathrm{SiO}_{4}$.

\subsection{Photo-catalytic degradation process}

$40 \mathrm{ml}$ of the dye solution (10 ppm) was used as a model pollutant to determine the photocatalytic activity. 0.04 g catalyst was applied for degradation of $40 \mathrm{ml}$ solution. The solution was mixed by a magnet stirrer for 1 hour in darkness to determine the adsorption of the dye by catalyst and better availability of the surface. The solution was irradiated by a $400 \mathrm{~W}$ UV lamp which was placed in a quartz pipe in the middle of reactor. It was turned on after 1 hour stirring the solution and sampling (about $10 \mathrm{ml}$ ) was done every $15 \mathrm{~min}$. The samples were filtered, centrifuged and their concentration was determined by UV-Visible spectrometry.

\subsection{Synthesis of polymeric nanocomposite}

For preparation of polymer-Co $\mathrm{SiO}_{4}$ nanocomposites, $4 \mathrm{~g}$ of $\mathrm{PSu}$ (or PS) was dissolved in $10 \mathrm{~mL}$ of dichloromethane and then $\mathrm{Co}_{2} \mathrm{SiO}_{4}(1 \mathrm{~g})$ was dispersed in $10 \mathrm{~mL}$ of dichloromethane with ultrasonic waves (20 min, $70 \mathrm{~W}$ ). The dispersion of $\mathrm{Co}_{2} \mathrm{SiO}_{4}$ was then added to the polymer solution slowly. The solution was mixed under stirring for $24 \mathrm{~h}$. For the preparation of samples for UL-94 test after stirring, the product was casted on a template with dimension $130 \times 13 \mathrm{~mm}$ and after about $48 \mathrm{~h}$ of solvent evaporation; the nanocomposite was placed in the vacuum oven for another $5 \mathrm{~h}$ for removal of residual traces of solvent. The final sheets for the test 
are $130 \times 13 \times 1.6 \mathrm{~mm}$ in dimension. In UL-94 a bar shape specimen of plastic $130 \times 13 \times 1.6 \mathrm{~mm}$ is positioned vertically and held from the top. A Bunsen burner flame is applied to the specimen twice (10 s each). A V-0 classification is given to material that is extinguished in less than $10 \mathrm{~s}$ after any flame application, drips of particles are allowed as long as they are not inflamed. A V-1 classification is received by a sample with maximum combustion time $<30 \mathrm{~s}$. Drips of particles are allowed as long as they are not inflamed. The sample is classified V-2 if it satisfies the combustion time criteria of V-1, but flaming drips are allowed. Materials are ranked as N.C. in UL-94 tests when the maximum total flaming time is above $50 \mathrm{~s}$.

\section{Results and discussion}

Fig.2 shows XRD pattern of product without calcination. It can be observed that amorphous product was prepared. The composition of the $\mathrm{Co}_{2} \mathrm{SiO}_{4}$ nanocomposite which obtained after calcination was investigated by XRD and it is shown in Fig. 3. It confirms presence of monoclinic phase of $\mathrm{Co}_{2} \mathrm{SiO}_{4}$ (JCPDS No.70-2280, space group: $\mathrm{Cc}$ ) in the pattern. The calculated crystalline size from Scherrer equation, $D_{c}=K \lambda / \beta \operatorname{Cos} \theta$, where $\beta$ is the width of the observed diffraction peak at its half maximum intensity (FWHM), K is about 0.9 , and $\lambda$ is the Xray wavelength $\left(\mathrm{CuK}_{\alpha}\right.$ radiation, equals to $\left.0.154 \mathrm{~nm}\right)$ was about $35 \mathrm{~nm}$.

The effect of various capping agent on the particle size was investigated and it was observed using just ethylene glycol nucleation was faster than crystal growth and nanoparticles were obtained. Fig. 4 illustrates SEM images of the as-synthesized $\mathrm{Co}_{2} \mathrm{SiO}_{4}$ nanoparticles (in different magnifications) obtained by ethylene glycol demonstrates mono-disperse product with average diameter size between 10-20 nm were prepared.

Fig. 5a and 5b illustrate SEM images of the product obtained by oxalic acid, which confirms formation of nanoparticles with mediocre size less than 50nm. Fig. 5c and 5d exhibit SEM images of $\mathrm{Co}_{2} \mathrm{SiO}_{4}$ that achieved by succinic acid which approve the size of particles are higher than oxalic acid and agglomerated nanostructures were synthesized. It is observed that the agglomeration size increase to $90 \mathrm{~nm}$, in two conditions there are 
agglomerated particles and nanoparticles. The balance between nucleation rate and growth rate which determines final particle size and morphology depend on precursor.

Effect of other capping agents on the particle size was also investigated. Figs. 6a-b illustrate SEM images of the prepared $\mathrm{Co}_{2} \mathrm{SiO}_{4}$ by citric acid and confirm mediocre size of nanoparticles is about $70 \mathrm{~nm}$. Figs. 6c-d show SEM images of the synthesized product with maleic acid and approve formation of nanoparticles with average particle size less than $20 \mathrm{~nm}$.

Figs. 7a depicts SEM image of the prepared poly styrene- $\mathrm{Co}_{2} \mathrm{SiO}_{4}$ nanocomposite. It seems polymeric chains cover the nanoparticles and just smooth surface was observed. Figs. 7b-d illustrate SEM images of the poly sulfone- $\mathrm{Co}_{2} \mathrm{SiO}_{4}$ and confirm appropriate dispersion of nanoparticles (mediocre size around $60 \mathrm{~nm}$ ) in the poly sulfone matrix.

For better estimation of particle size, transmission electron microscopy was used. TEM image of $\mathrm{Co}_{2} \mathrm{SiO}_{4}$ nanoparticles is shown in Fig 8 and confirms synthesis of nanoparticles with average particle size about $20 \mathrm{~nm}$.

Energy dispersive spectroscopy analysis was performed to monitor the average elemental composition of the asprepared nanoparticles and confirm the purity of the product. Fig.9 shows the typical EDS pattern of the sample that confirmed the presence of $\mathrm{Si}, \mathrm{Co}$ and $\mathrm{O}$ elements and there were no other peaks for impurities.

FT-IR spectra of the as-prepared products without calcinations and after calcinations are shown in Fig. 10a and $10 \mathrm{~b}$ respectively. The absorption band at $1065 \mathrm{~cm}^{-1}$ is assigned to the Si-O. Peak at $1675 \mathrm{~cm}^{-1}$ is related to carboxyl stretching mode. The absorption bands at 469, 580 and $669 \mathrm{~cm}^{-1}$ are assigned to the Co-O (metaloxygen) stretching mode. Absorption at $1105 \mathrm{~cm}^{-1}$ is related to C-O of tetra-ethyl ortho-silicate precursor. The spectrum exhibits broad absorption peaks around $3400 \mathrm{~cm}^{-1}$, corresponding to the stretching mode of O-H group of adsorbed hydroxyl group and the weak band near $1600 \mathrm{~cm}^{-1}$ is assigned to $\mathrm{H}-\mathrm{O}-\mathrm{H}$ bending vibration 
mode due to the adsorption of moisture on the surface of nanoparticles. There are no other significant peaks related to precursors and other impurities. Fig. 11a and $11 \mathrm{~b}$ show the FT-IR spectra of the poly styrene$\mathrm{Co}_{2} \mathrm{SiO}_{4}$ and poly sulfone- $\mathrm{Co}_{2} \mathrm{SiO}_{4}$ respectively. Peaks around $2900-3000 \mathrm{~cm}^{-1}$ are responsible to aliphatic C-H bonds and peaks at 3000-3100 $\mathrm{cm}^{-1}$ are related to aromatic carbon-hydrogen bonds. Absorptions around 1400 and $1600 \mathrm{~cm}^{-1}$ are related to aromatic $\mathrm{C}=\mathrm{C}$ bonds in both poly sulfone and poly styrene matrices.

Room temperature magnetic properties of samples were studied using AGFM system. Hysteresis loop of magnetic nanoparticles is shown in Fig. 12. As-synthesized nanoparticles show magnetic behaviour and have a saturation magnetization of $0.02 \mathrm{emu} / \mathrm{g}$ and a coercivity about zero Oe. The magnetic property of the prepared nanocomposites is suitable for re-generable and reusable magnetic heterogeneous catalyst.

The absorption spectrum of the titanium dioxide under UV-visible was investigated, diffuse reflectance spectroscopy (DRS) is depicted in Fig. 13. Band-gap of $\mathrm{Co}_{2} \mathrm{SiO}_{4}$ nanoparticles was estimated by Tauc's equation using the absorption data $\alpha=\alpha_{0}(\mathrm{~h} v-\mathrm{Eg})^{\mathrm{n}} / \mathrm{h} v$ where $\alpha$ is absorption coefficient, $\alpha_{0}$ and $\mathrm{h}$ are the constants, $\mathrm{h} v$ is the photon energy, Eg is the optical band gap of the material, and $\mathrm{n}$ depends on the type of electronic transition and can have any value between 0.5 to 3 . The energy gap of the sample (Eg) has been distinguished by extrapolating the linear portion of the plots of $(\alpha h v)^{2}$ against hv to the energy axis. The approximation of band gap for nanoparticles is $3.3 \mathrm{eV}$ [9-13].

The photo-catalytic activity of the $\mathrm{Co}_{2} \mathrm{SiO}_{4}$ nanoparticles was evaluated by monitoring the degradation of three azo dyes in an aqueous solution, under irradiation with UV light. The changes in the concentration of dye are illustrated in Fig. 14a-c. Methyl orange, Acid Black and Acid Brown were degraded about 85, 93 and 95\% in 120 min respectively. Organic dyes decompose to carbon dioxide, water and other less toxic or nontoxic residuals [9-13]. Fig. 14d shows degradation of the three various dyes after 120 min exposure to the $\mathrm{Co}_{2} \mathrm{SiO}_{4}$ nanocomposite. 
Thermal stability of the poly styrene and poly sulfone and their nanocomposite were investigated by thermogravimetric analysis. TGA curve of $\mathrm{PS}_{-} \mathrm{Co}_{2} \mathrm{SiO}_{4}$ nanocomposite is shown in Fig. 15. Because of the present of $\mathrm{Co}_{2} \mathrm{SiO}_{4}$, thermal decomposition of the nanocomposite is shifted towards the higher temperatures. Dispersed $\mathrm{Co}_{2} \mathrm{SiO}_{4}$ nanoparticles can act as barriers which slow down product volatilization and thermal transport during decomposition of the polymer.

Differential scanning calorimeter (DSC) of $\mathrm{PS}_{-} \mathrm{Co}_{2} \mathrm{SiO}_{4}$ nanocomposite is shown in Fig. 16 that confirms endothermic decomposition of nanocomposite that is suitable for flame retardancy.

TGA curves of PSu-Co ${ }_{2} \mathrm{SiO}_{4}$ nanocomposite is illustrated in Fig. 17. Due to dispersion of $\mathrm{Co}_{2} \mathrm{SiO}_{4}$, thermal decomposition of the nanocomposite is also changed towards the higher temperatures. $\mathrm{Co}_{2} \mathrm{SiO}_{4}$ nanoparticles also can act as obstruction which slows polymer volatilization and thermal transport during heating of the nanocomposite.

DSC of PSu-Co ${ }_{2} \mathrm{SiO}_{4}$ nanocomposite is depicted in Fig. 18 that also approves endothermic decomposition of nanocomposite that is appropriate for flame retardant properties.

The outcomes of UL-94 tests for PS and PS- $\mathrm{Co}_{2} \mathrm{SiO}_{4}$ are N.C and V-0 respectively. The results show that the $\mathrm{Co}_{2} \mathrm{SiO}_{4}$ can enhance the flame retardant property of the both poly sulfone and poly styrene matrices. According to the UL-94 test, nanoparticles have been appropriately interacted to PSu and PS matrices. Nanoparticles can play the role of a barrier layer; this magnetic barrier layer prevents heat or flame from reaching to the sample. High surface of $\mathrm{Co}_{2} \mathrm{SiO}_{4}$ have suitable interaction with functional groups of PSu. Because of mentioned interaction, nanoparticles appropriately disperse in polymer matrix. In the presence of flame and occurrence of polymer decomposition, magnetic nanoparticles remain together (show resistance to drip falling) and build a barrier. This obstruction prevents reaching oxygen and flame to the sample [14-16].

\section{Conclusions}


$\mathrm{Co}_{2} \mathrm{SiO}_{4}$ nanoparticles were synthesized via a simple Pechini sol-gel method. The effect of various capping agents on the morphology and particle size of the products was investigated. AGFM confirms that nanoparticles exhibit magnetic behaviour. The photocatalytic behaviour of $\mathrm{Co}_{2} \mathrm{SiO}_{4}$ nanocomposite was evaluated using the degradation of three various azo dyes under UV light irradiation. The results show that Pechini method is a suitable method for preparation of $\mathrm{Co}_{2} \mathrm{SiO}_{4}$ nanocomposites as a candidate for photocatalytic applications. For preparation of polymeric nanocomposite $\mathrm{Co}_{2} \mathrm{SiO}_{4}$ nanoparticles were added to poly styrene and poly sulfone matrices. Outcomes confirm that nanoparticles appropriately enhanced both thermal stability and flame retardant property of the PS and PSu matrices.

\section{Acknowledgments}

Authors are grateful to the council of Iran National Science Foundation (91053846) and University of Kashan for supporting this work by Grant No (159271/979). 


\section{References}

[1] M. Stoia, M. Stefanescu, T. Dippong, O. Stefanescu, P. Barvinschi. J Sol-Gel Sci Technol 54, 49 (2010)

[2] H Cui, M. Zayat, D. Levy. J Sol-Gel Sci Techn 40, 83 (2006)

[3] A. Sazonov, M. Meven, V. Hutanu, G. Heger, T. Hansen, A. Gukasov. Acta Cryst. B65, 664 (2009).

[4] T. LUTZ, C. ESTOURN`ES AND J.L. GUILLE . J Sol-Gel Sci Technol 13, 929 (1998)

[5] H. Taguchi, Y. Takeda, H. Shibahara Materials Letters 52 , 412 (2002)

[6] Q. Tang, R. Dieckmann Journal of Crystal Growth 317, 119 (2011)

[7] G. Bagnasco, C. Cammarano, Maria Turco, S. Esposito, A. Aronne, P. Pernice. Thermochimica Acta 471 $51(2008)$

[8] J. A. Mary, A. Manikandan, L. J. Kennedy, M. Bououdina, R. Sundaram, J. J. Vijaya, Trans. Nonferrous Met. Soc. China 24, 1467 (2014)

[9]. S.R. Yousefi, D. Ghanbari, M. Salavati-Niasari, M. Hassanpour, J. Mater. Sci. Mater. Electron, 27,1244 (2016)

[10]. A. Abbasi, D. Ghanbari, M. Salavati-Niasari, M. Hamadanian, J. Mater. Sci. Mater. Electron (in press), (2016)

[11]. A. Esmaeili-Bafghi-Karimabad, D. Ghanbari, M. Salavati-Niasari, L. Nejati-Moghadam, S. Gholamrezaei, J. Mater. Sci. Mater. Electron. 26, 6970 (2015)

[12]. J. Saffari, N. Mir, D. Ghanbari, K. Khandan-Barani, A. Hassanabadi, M R Hosseini-Tabatabaei J. Mater. Sci. Mater. Electron, 26, 9591 (2015) 
[13]. H. Momenian, S. Gholamrezaei, M. Salavati-Niasari, B. Pedram, F. Mozaffar, D. Ghanbari, J. Cluster Sci. $24,1031(2013)$

[14]. D. Ghanbari, M. Salavati-Niasari, M. Ghasemi-Kooch, J. Ind. Eng. Chem. 20, 3970 (2014)

[15]. J. Saffari, D. Ghanbari, N. Mir, K. Khandan-Barani, J. Ind. Eng. Chem. 20, 4119 (2014)

[16]. J. Saffari, H. Shams, D. Ghanbari, A. Esmaeili, J. Cluster Sci. 25, 1225 (2014)

[17]. J. Huang, S. Liu, L. Kuang, Y. Zhao, T. Jiang, S. Liu, X. Xu, J. Environ. Sci. 25, 2487 (2013)

[18]. Y.-Q. Li, S.-Y. Fu, Y.-W. Mai, Polymer 47, 2127 (2006)

[19]. X. Wei, T. Xie, L. Peng, W. Fu, J. Chen, Q. Gao, G. Hong, D. Wang, J. Phys. Chem. C 115, 8637 (2011)

[20]. C. Hu, Z. Gao, X. Yang, Chem. Phys. Lett. 429, 513 (2006)

[21] F. Ansari, A. Sobhani , M. Salavati-Niasari, J Magn Magn Mater, 401, 362-369 (2016)

[22] A. Sobhani, M. Salavati-Niasari, J Alloys Compds, 617, 93-101 (2014)

[23] F. Ansari, A. Sobhani, M. Salavati-Niasari, RSC Adv ,4, 63946-63950 (2014)

[24] F. Ansari, F. Soofivand, M. Salavati-Niasari, Mater Charac, 103, 11-17 (2015) 


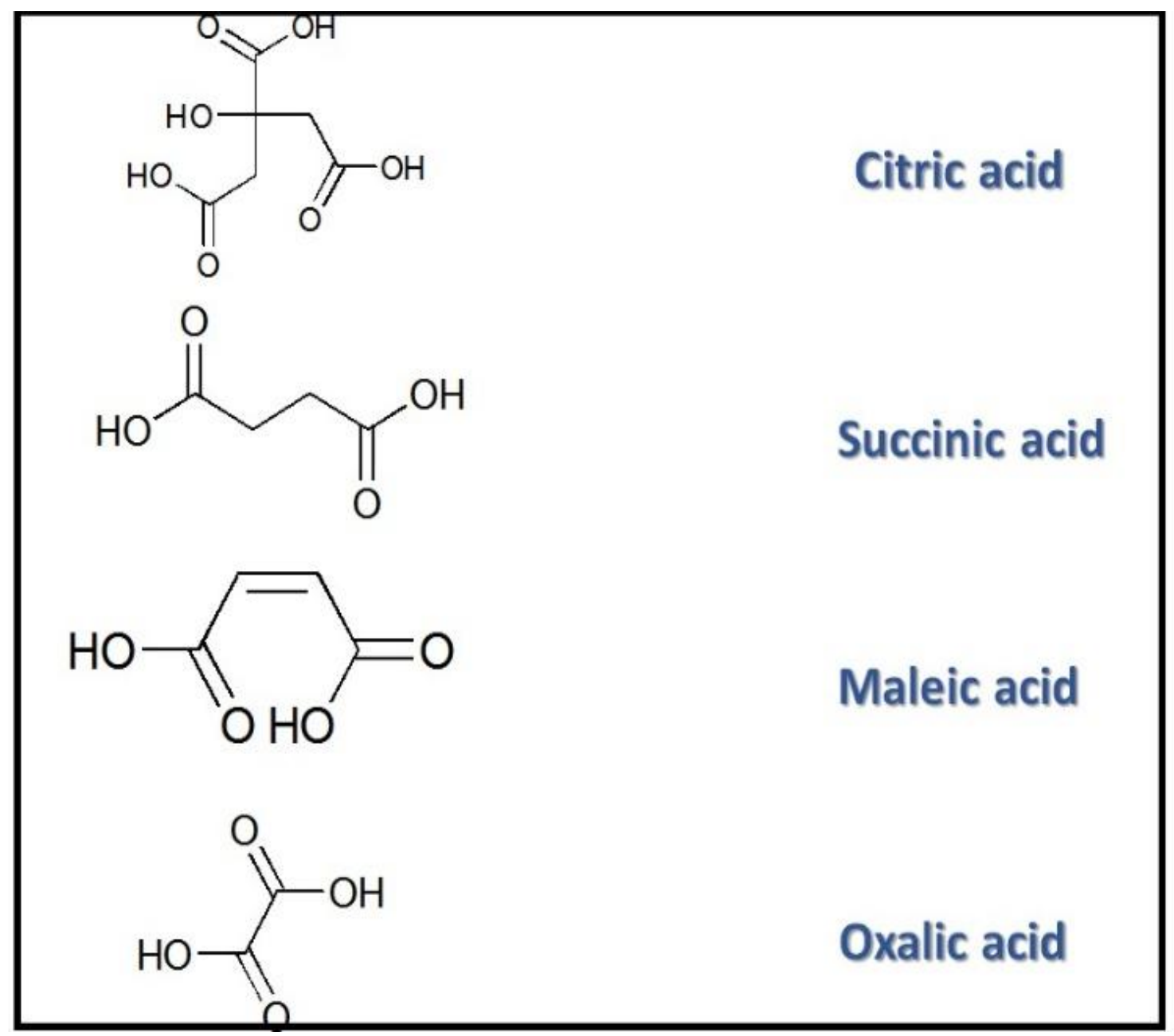

Figure 1. Various capping agents in Pechini reaction 


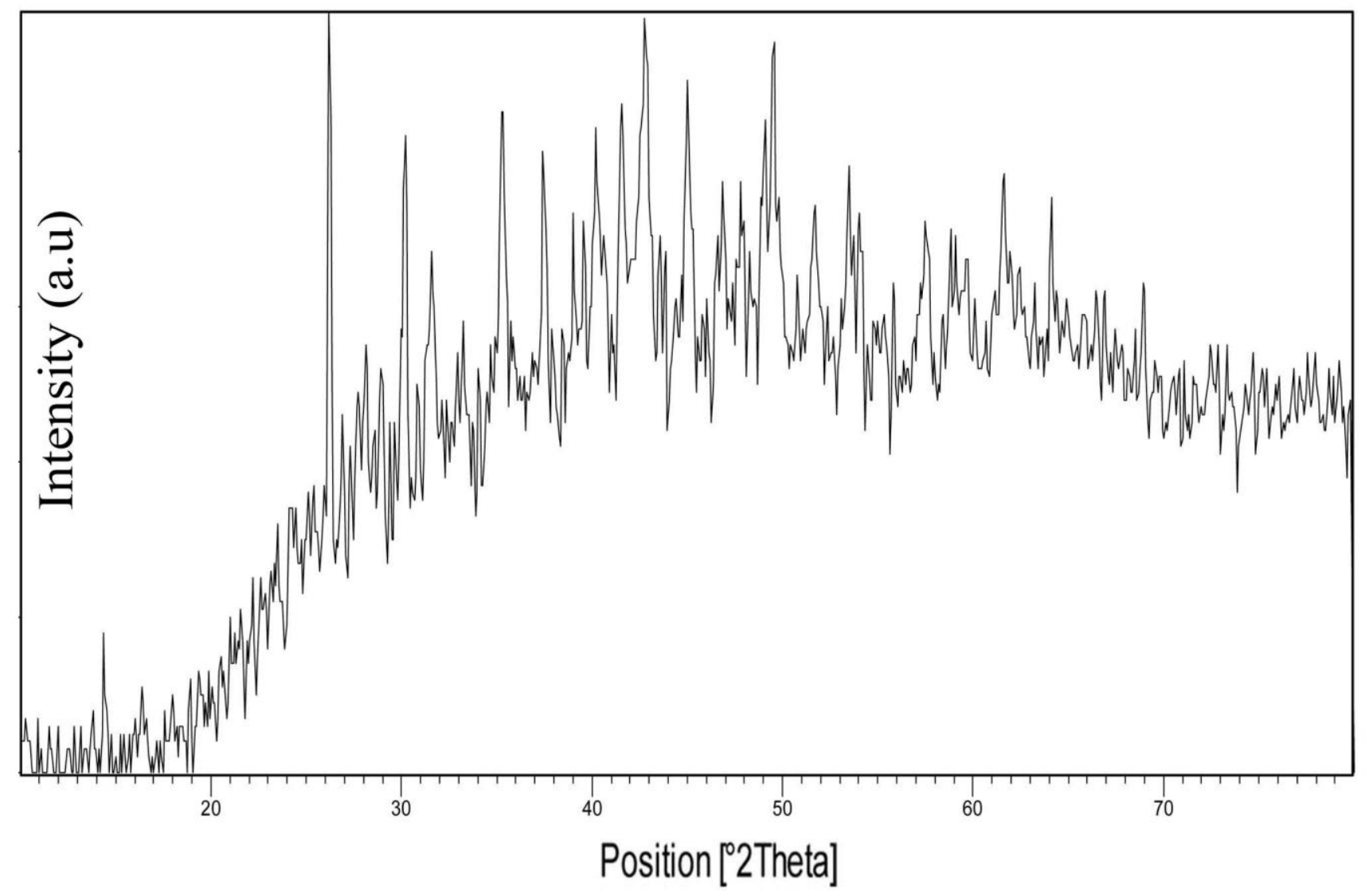

Figure 2. XRD pattern of product before calcination 


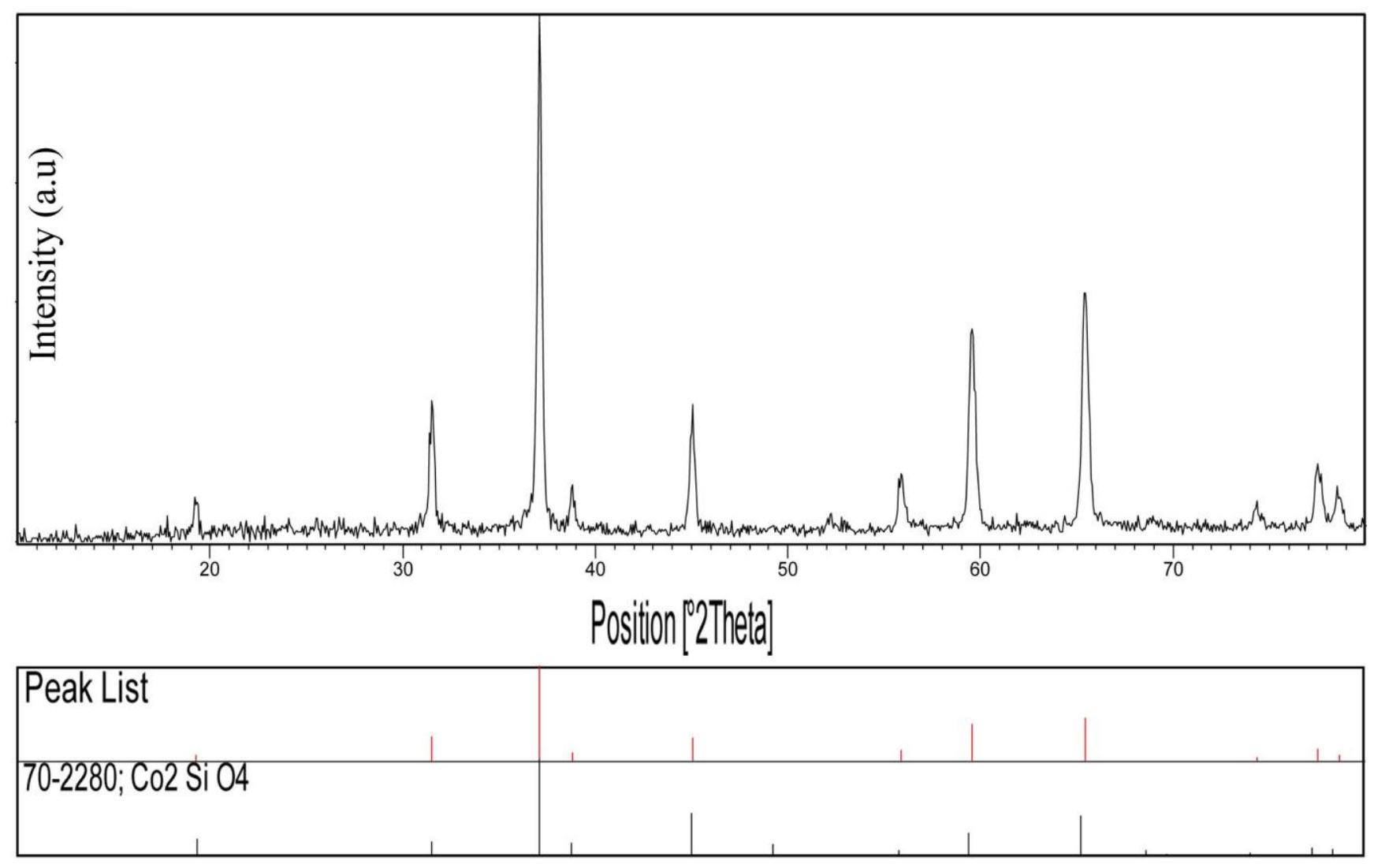

Figure 3. XRD pattern of $\mathrm{Co}_{2} \mathrm{SiO}_{4}$ nanoparticles 


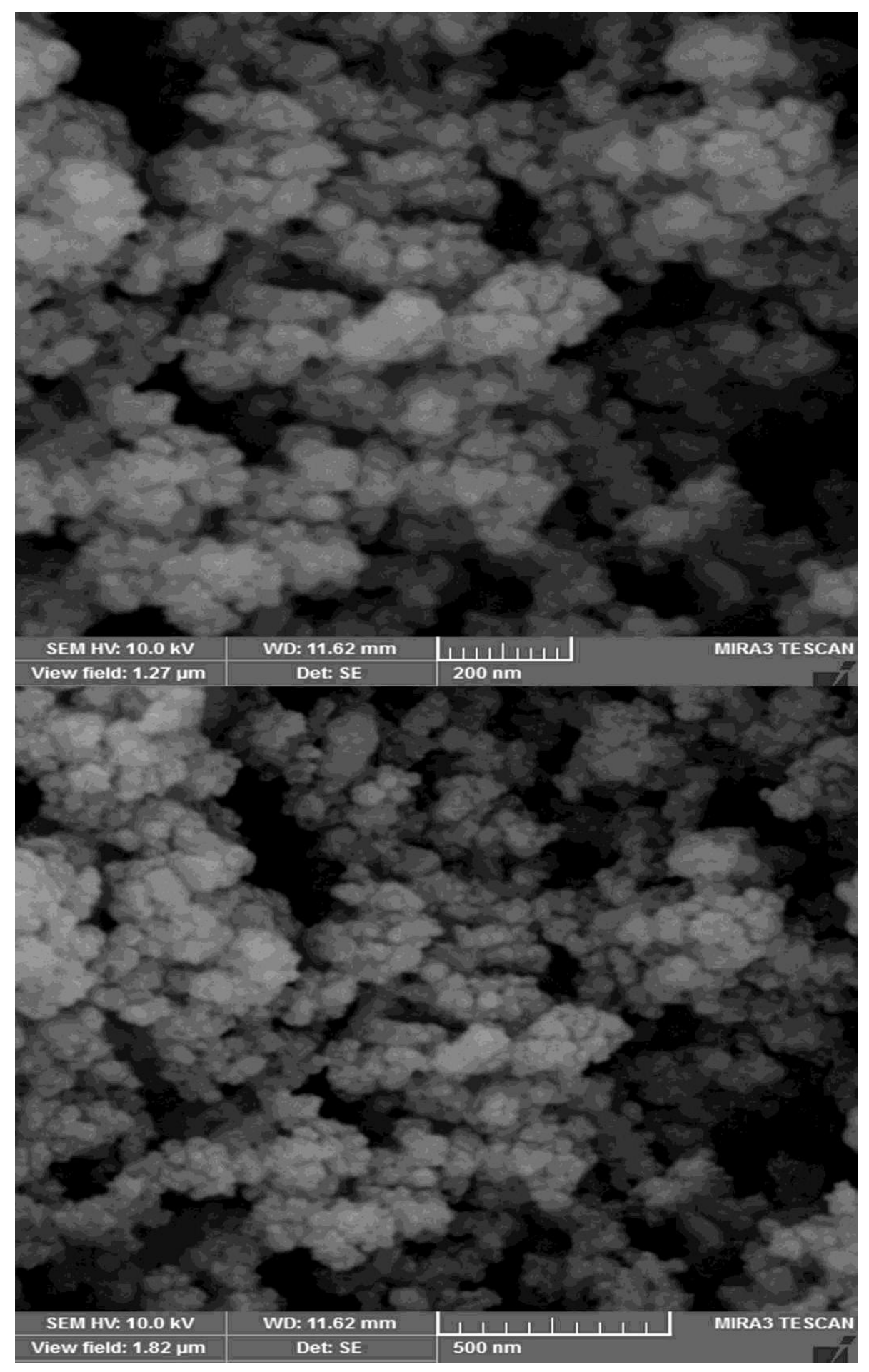

Figure 4. $\mathrm{SEM}$ images of $\mathrm{Co}_{2} \mathrm{SiO}_{4}$ nanoparticles 


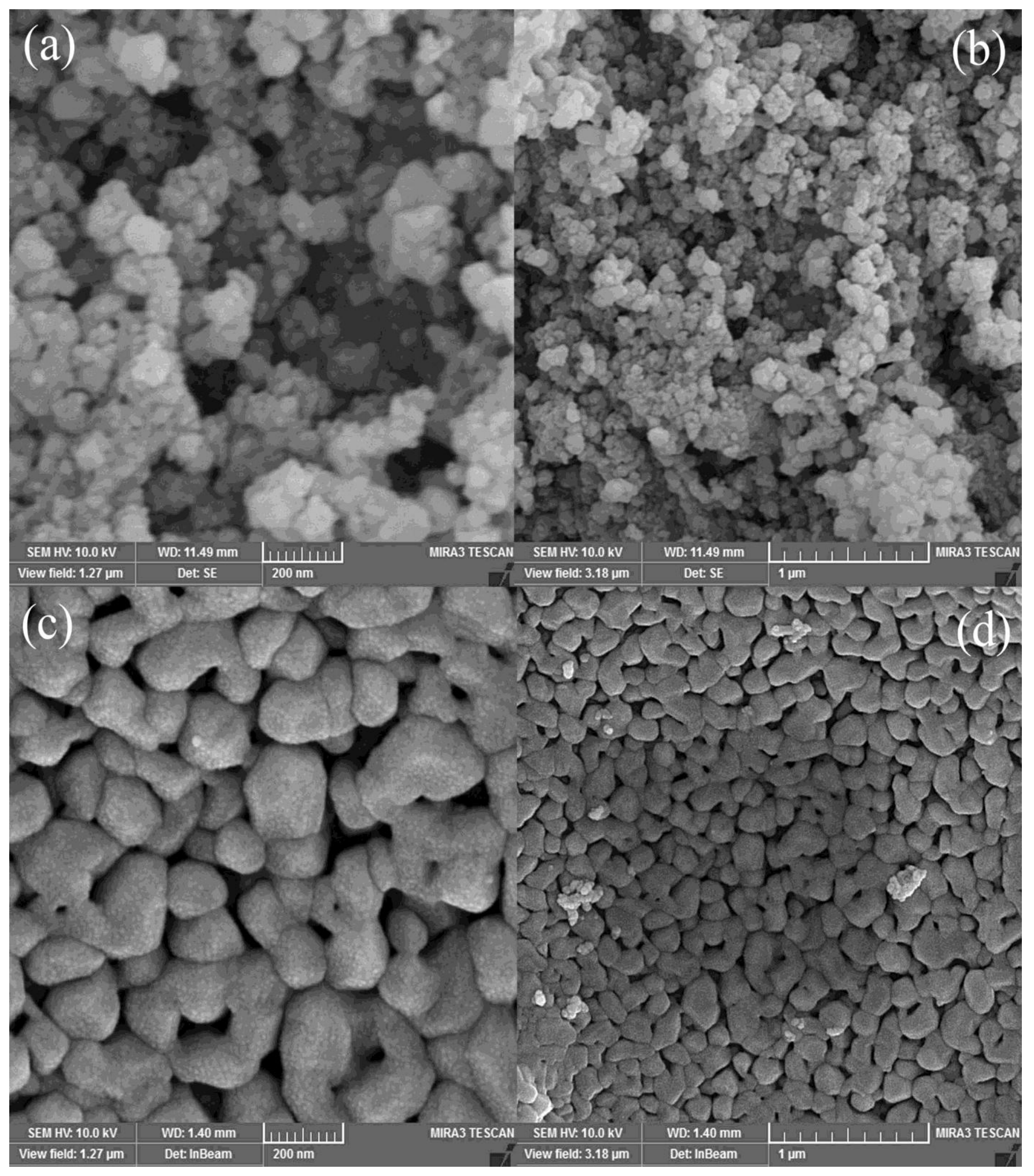

Figure 5. SEM images of products synthesized at presence of (a,b) Oxalic acid (b) Succinic acid 


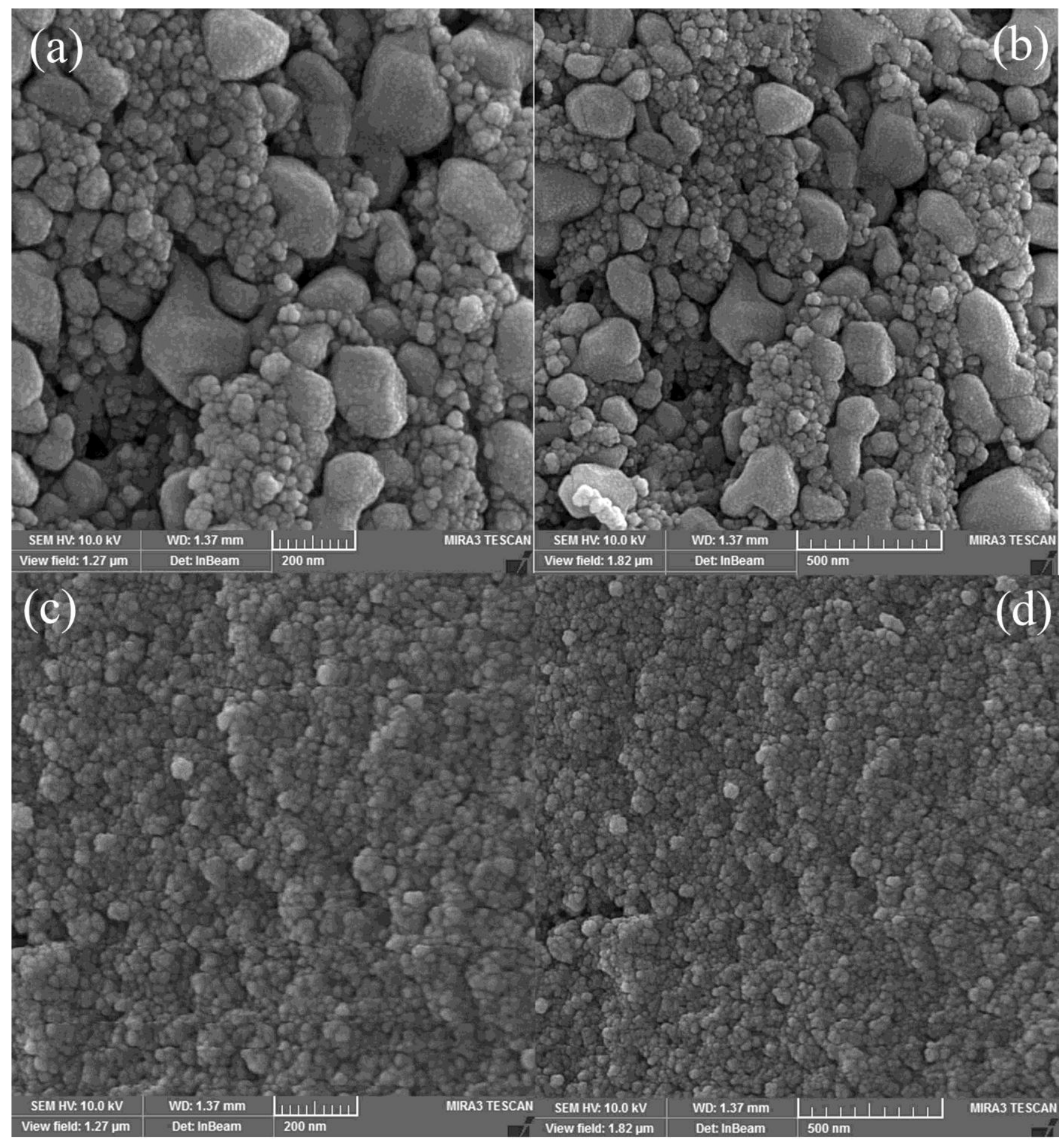

Figure 6. SEM images of nanoparticles obtained by $(a, b)$ citric acid (c, d) maleic acid 


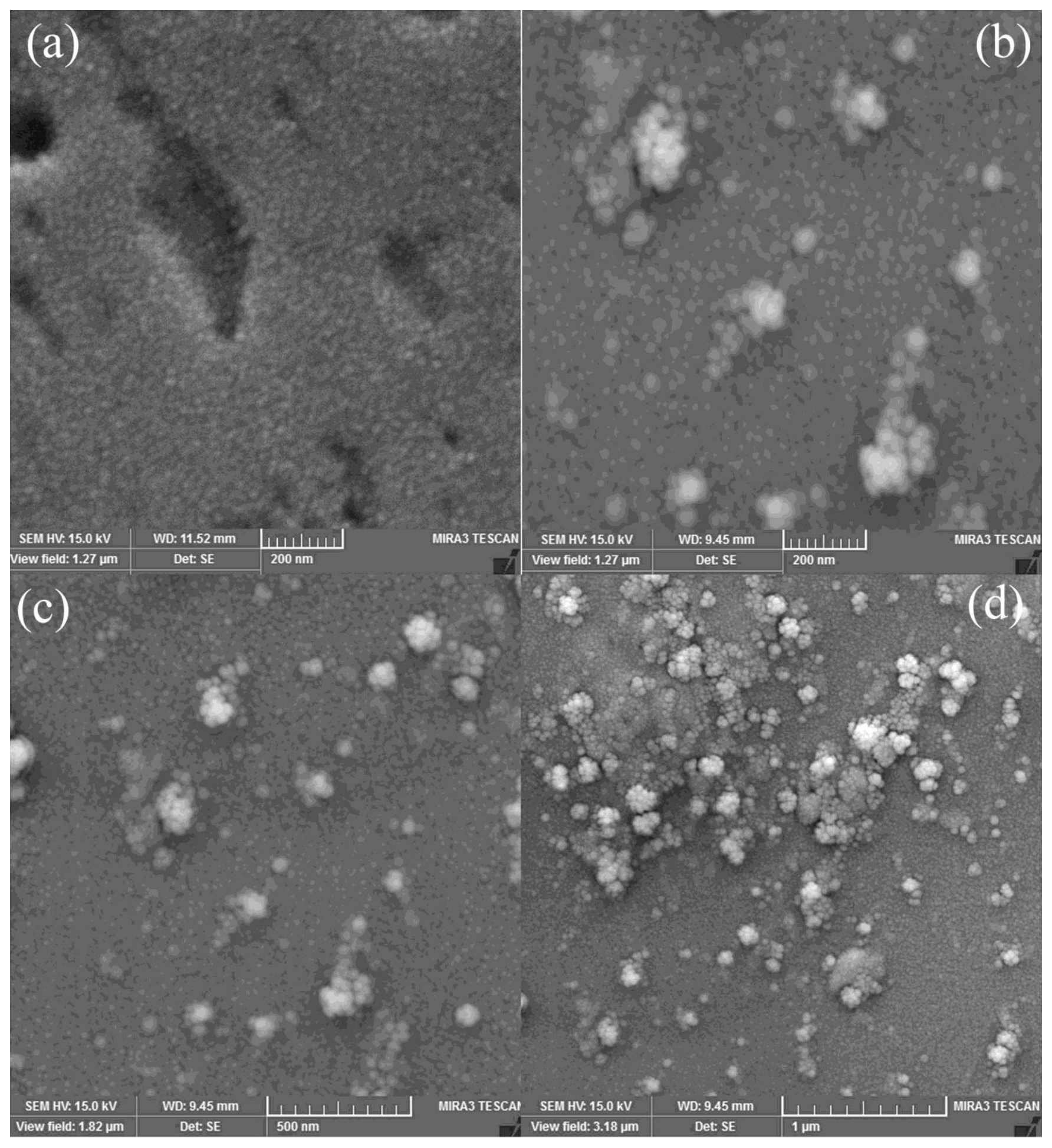

Figure 7. SEM images of (a) poly styrene- $\mathrm{Co}_{2} \mathrm{SiO}_{4}$ (b,c,d) poly sulfone- $\mathrm{Co}_{2} \mathrm{SiO}_{4}$ 


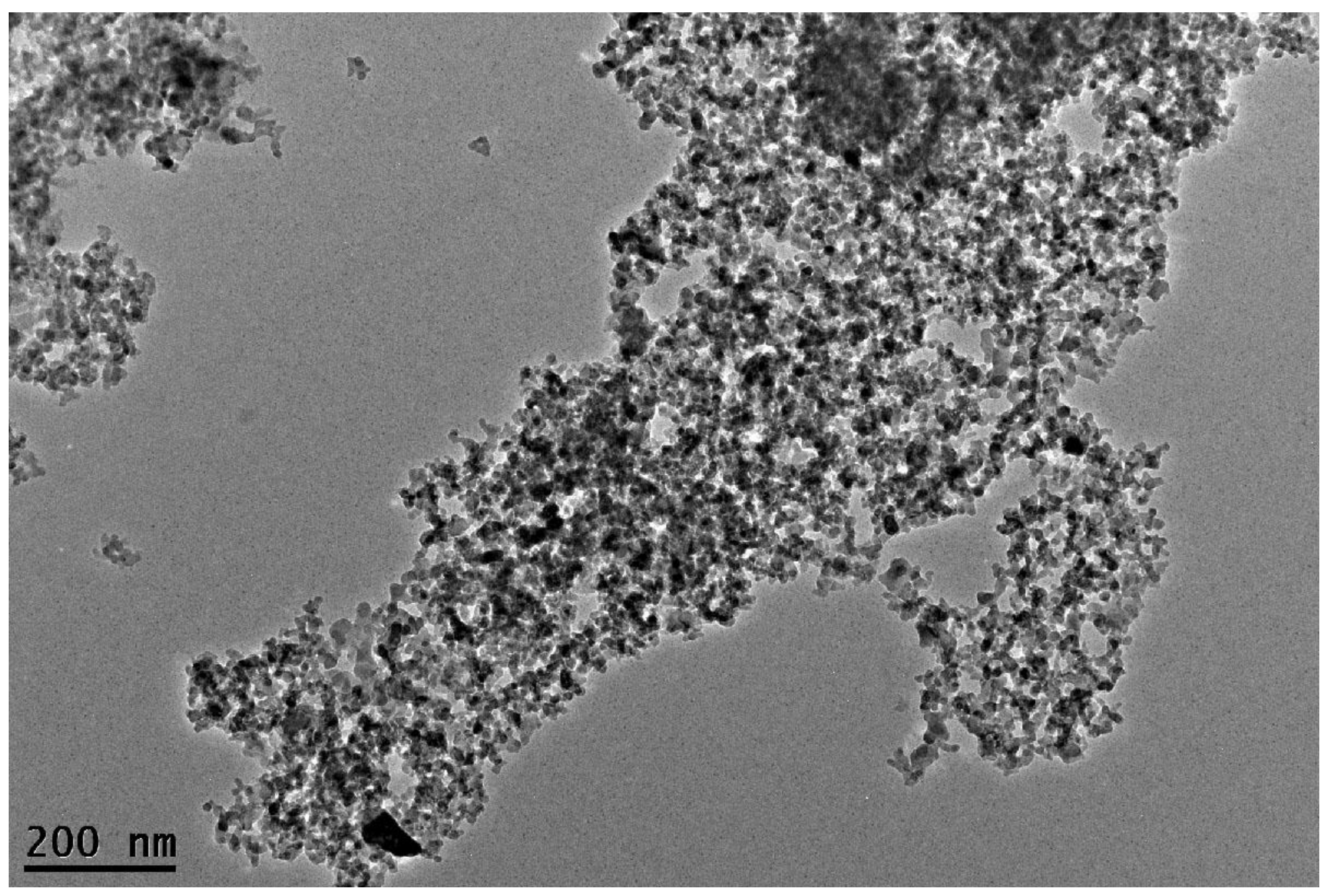

Figure 8. TEM image of $\mathrm{Co}_{2} \mathrm{SiO}_{4}$ nanoparticles 


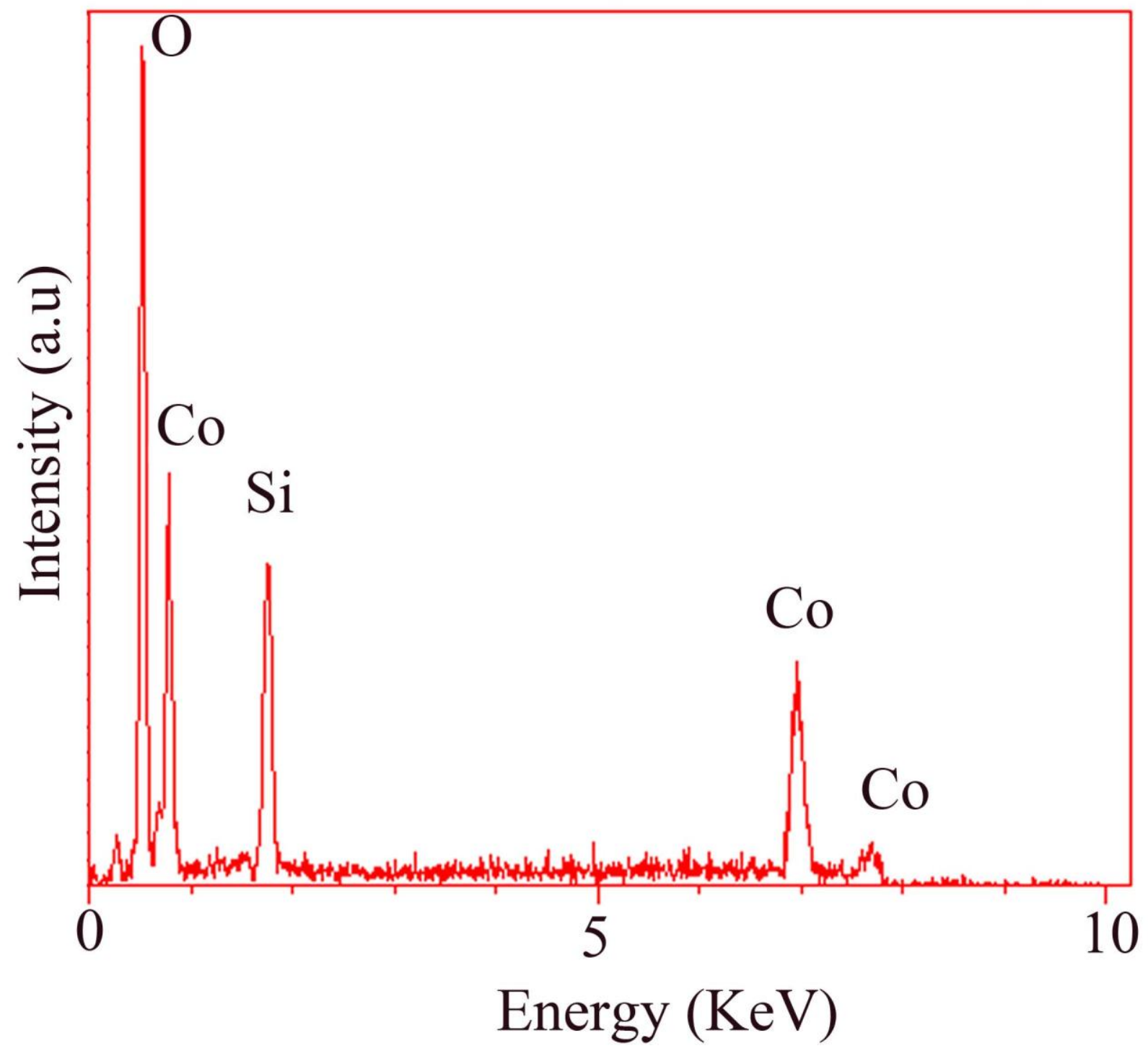

Figure 9. EDS analysis of $\mathrm{Co}_{2} \mathrm{SiO}_{4}$ nanoparticles 

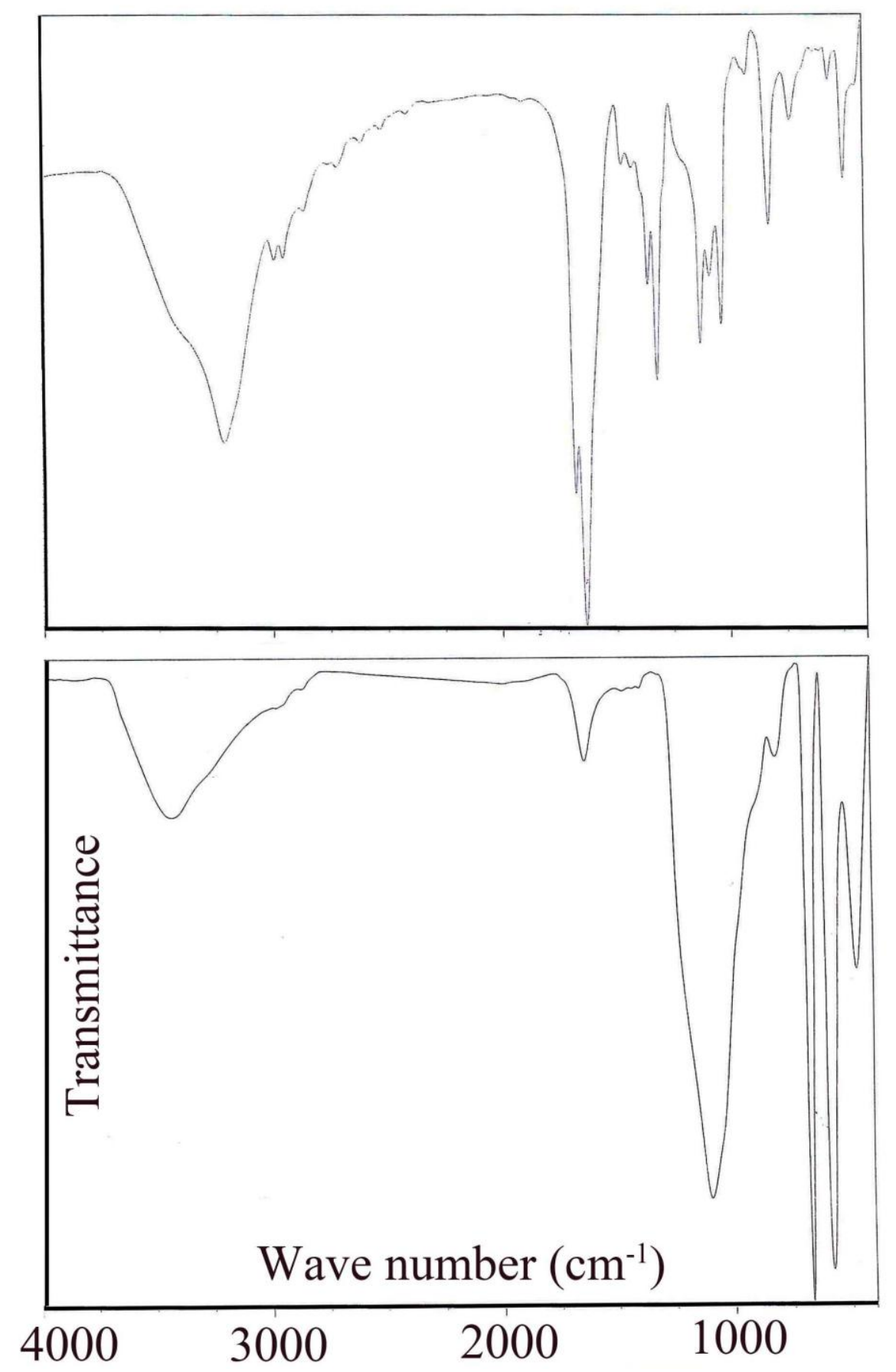

Figure 10. FT-IR spectra of products (a) before calcination (b) after calcination 

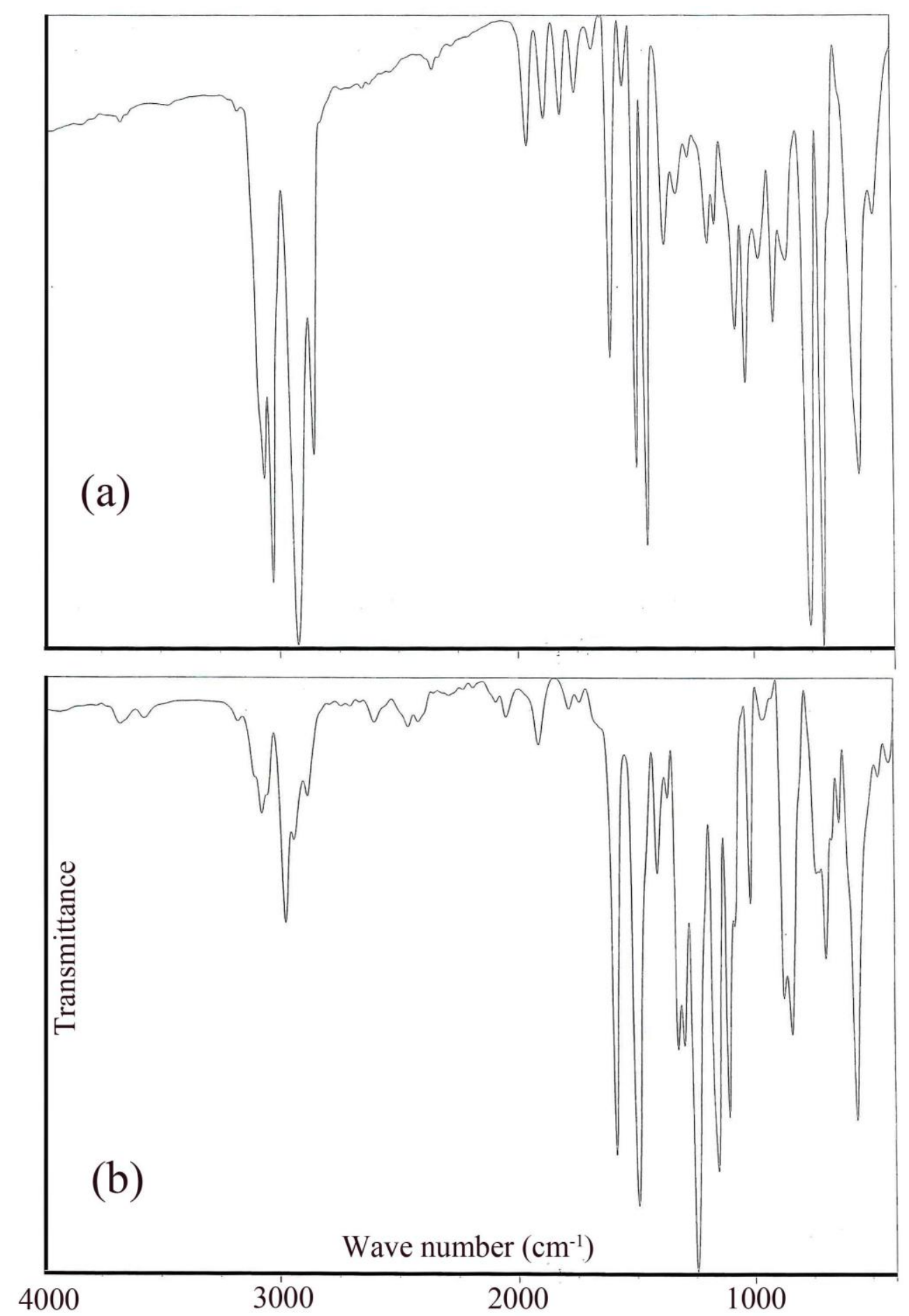

Figure 11. FT-IR spectra of nanocomposite (a) PS- $\mathrm{Co}_{2} \mathrm{SiO}_{4}$ (b) $\mathrm{PSu}-\mathrm{Co}_{2} \mathrm{SiO}_{4}$ 


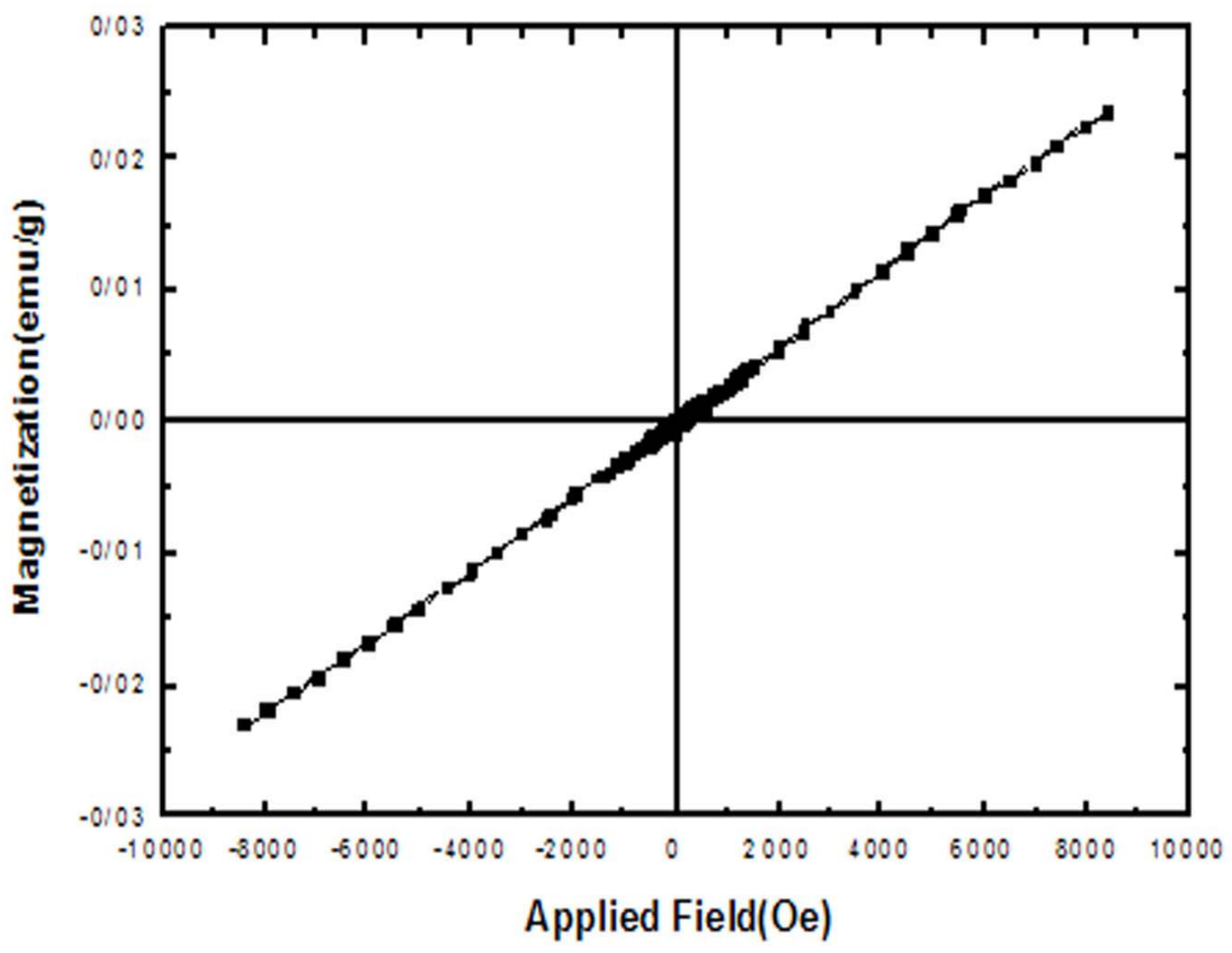

Figure 12. Room temperature magnetic curve of $\mathrm{Co}_{2} \mathrm{SiO}_{4}$ nanoparticles 


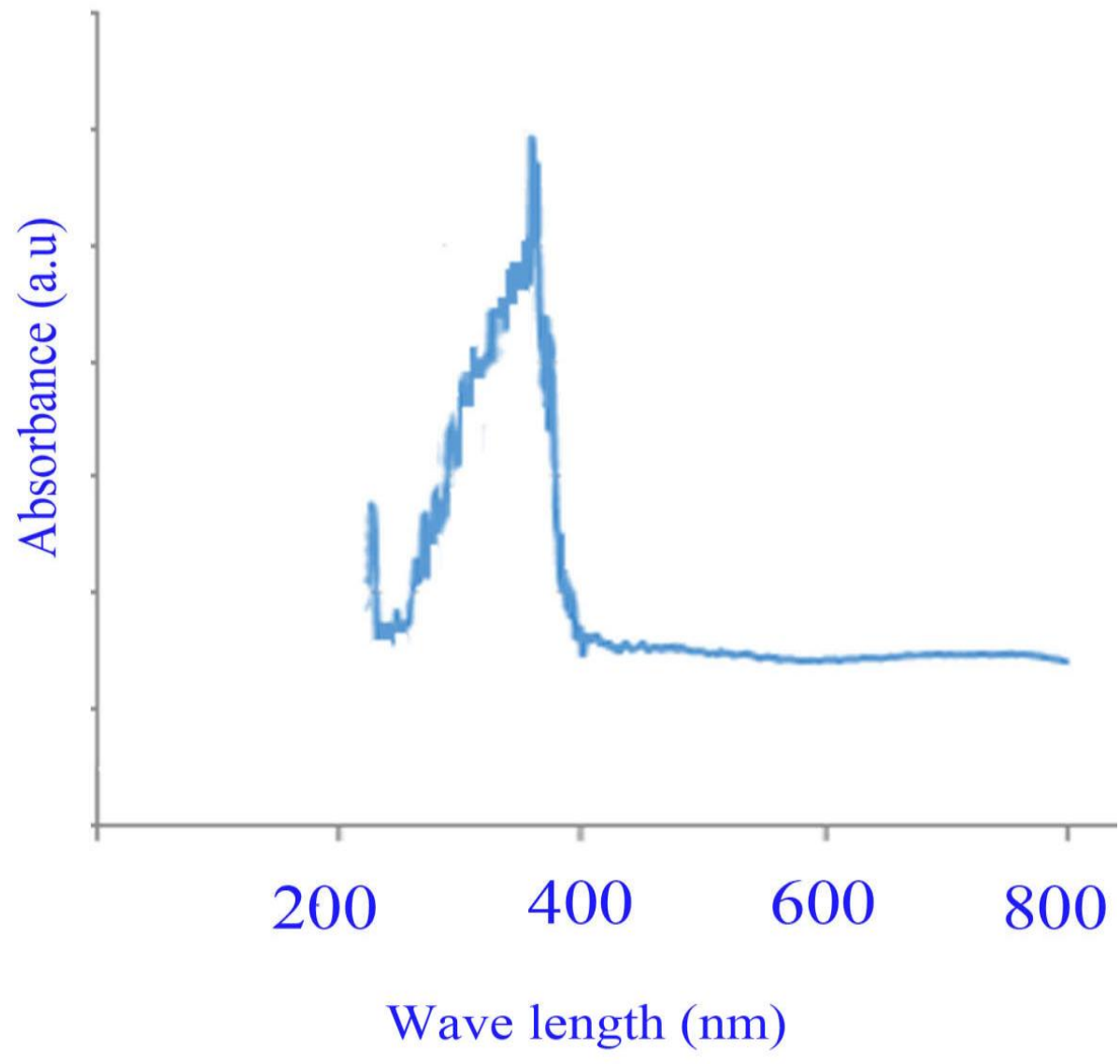

Figure 13. UV-Vis absorption spectrum of $\mathrm{Co}_{2} \mathrm{SiO}_{4}$ nanoparticles 

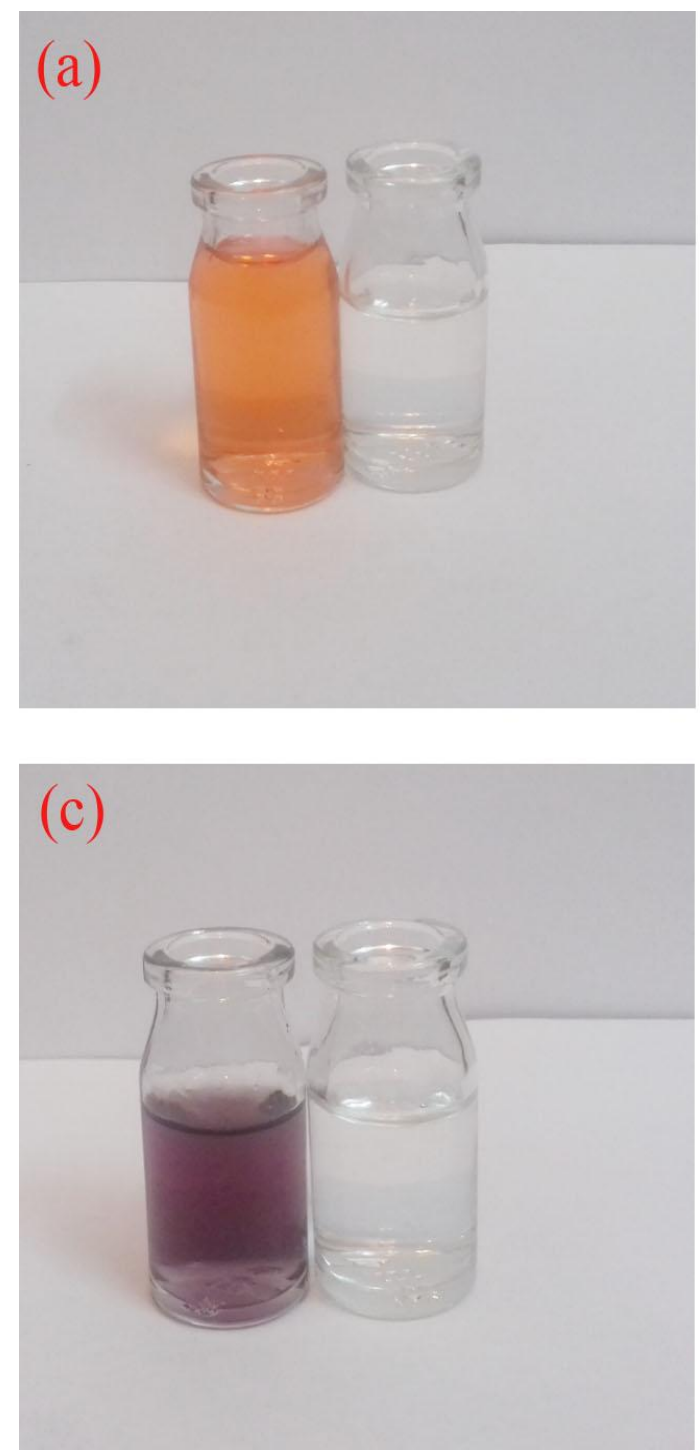

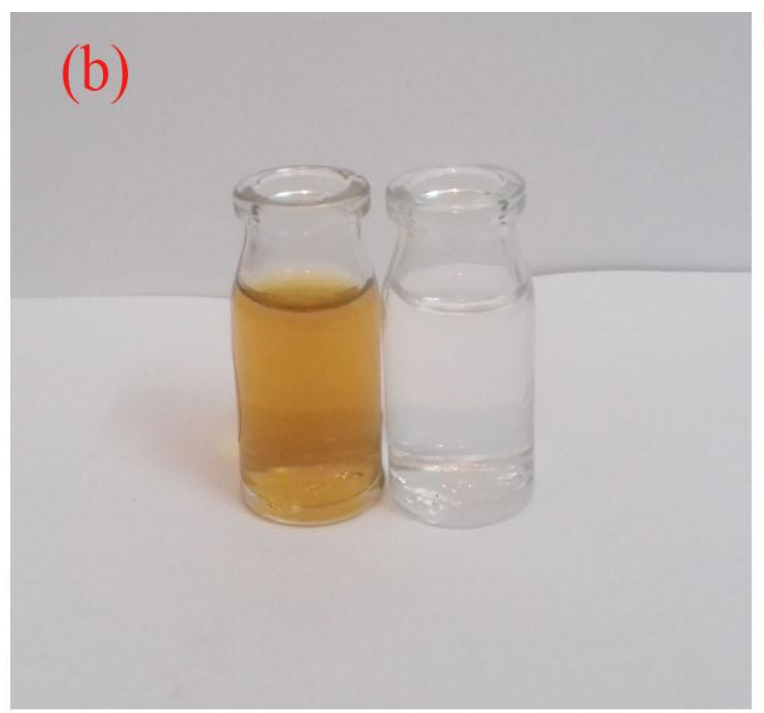

(d)

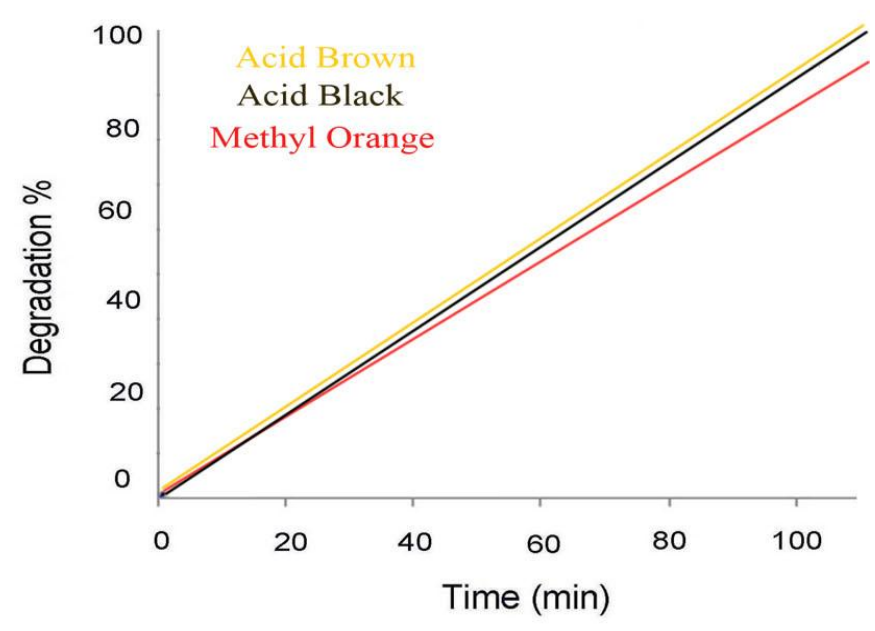

Figure 14. Photocatalytic activity of $\mathrm{Co}_{2} \mathrm{SiO}_{4}$ on degradation of (a) Methyl orange (b) Acid brown (c) Acid black (d) Degradation versus time 


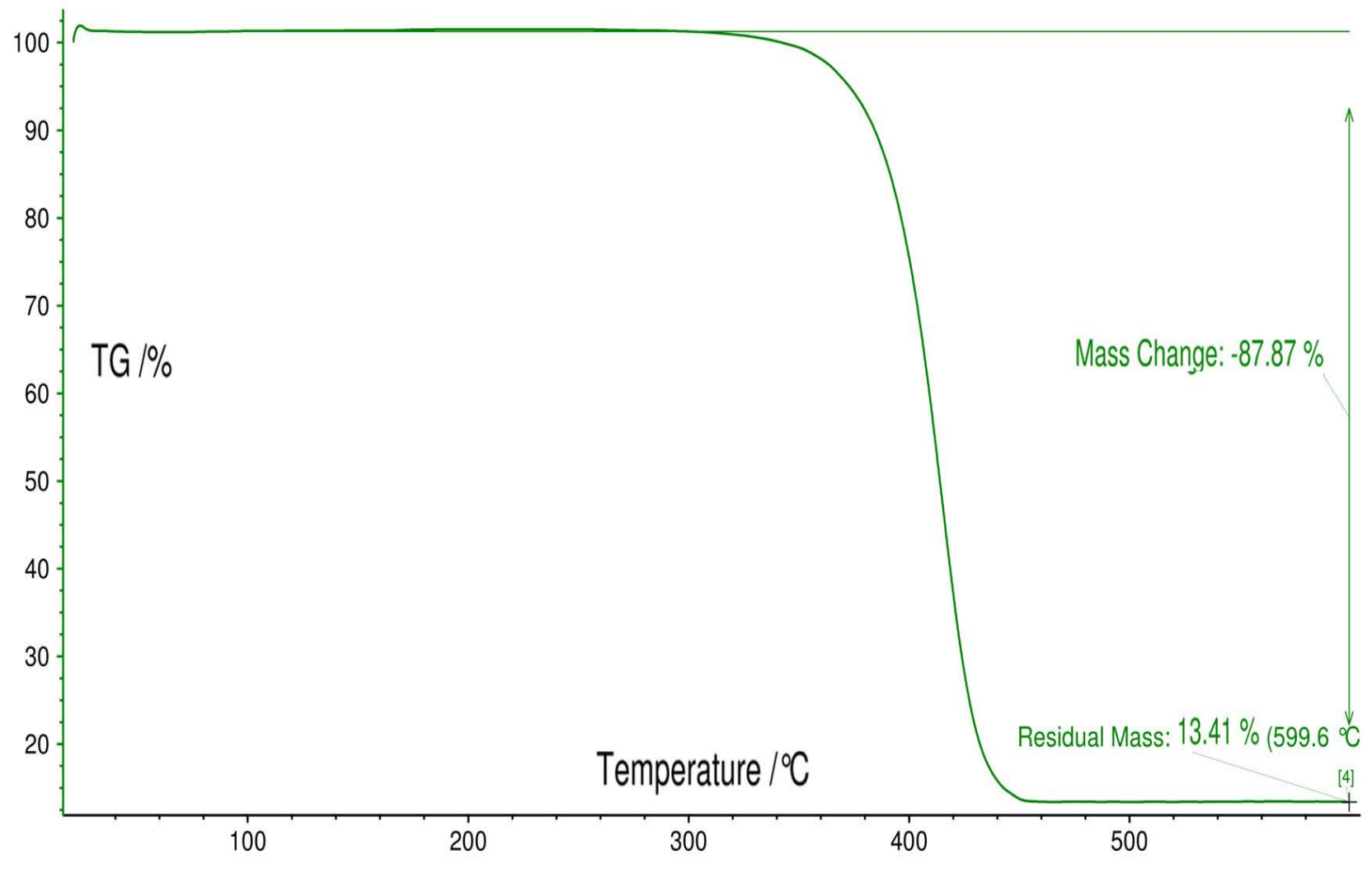

Figure 15. TGA of $\mathrm{PS}-\mathrm{Co}_{2} \mathrm{SiO}_{4}$ nanocomposite 


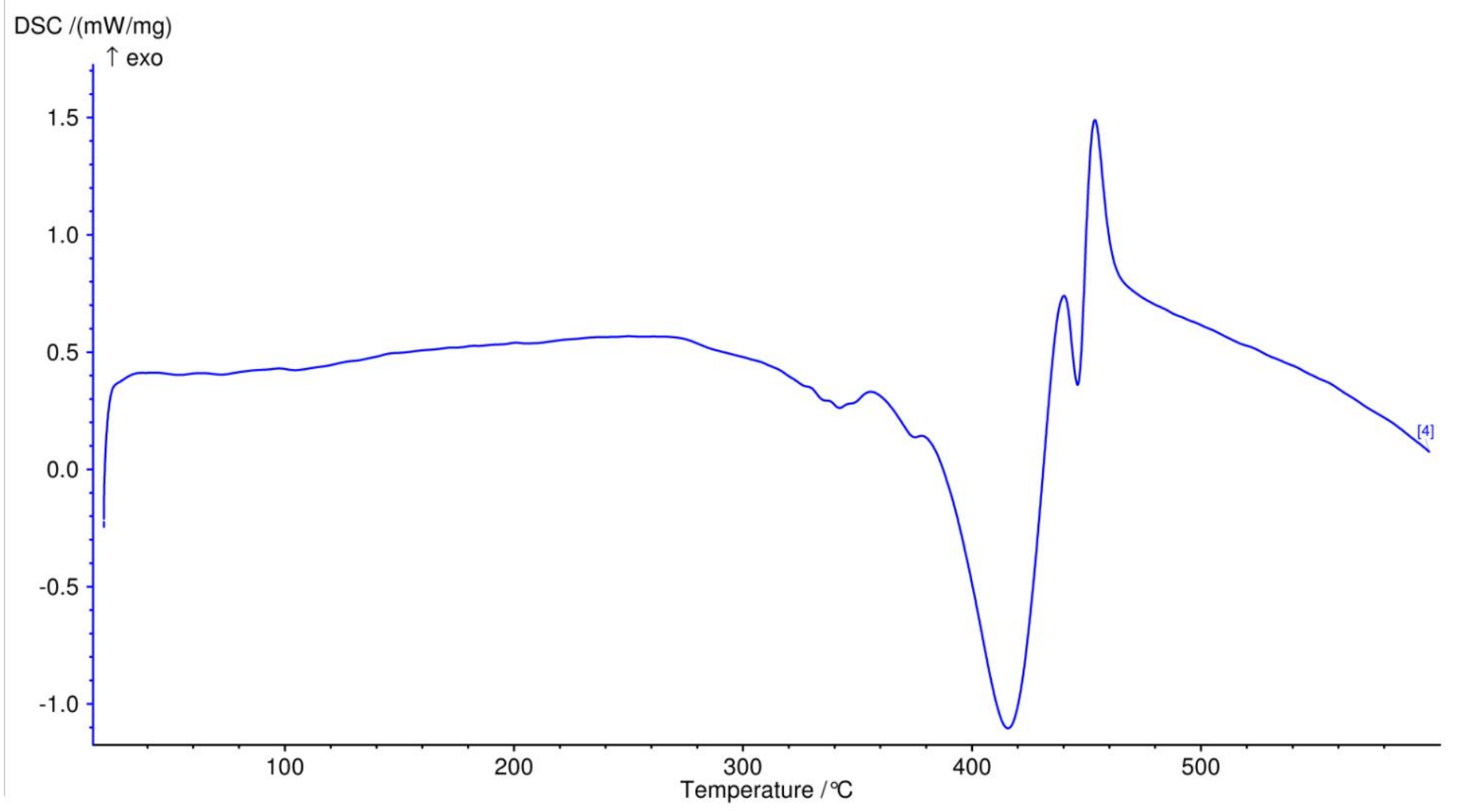

Figure 16. DSC analysis of $\mathrm{PS}-\mathrm{Co}_{2} \mathrm{SiO}_{4}$ nanocomposite 


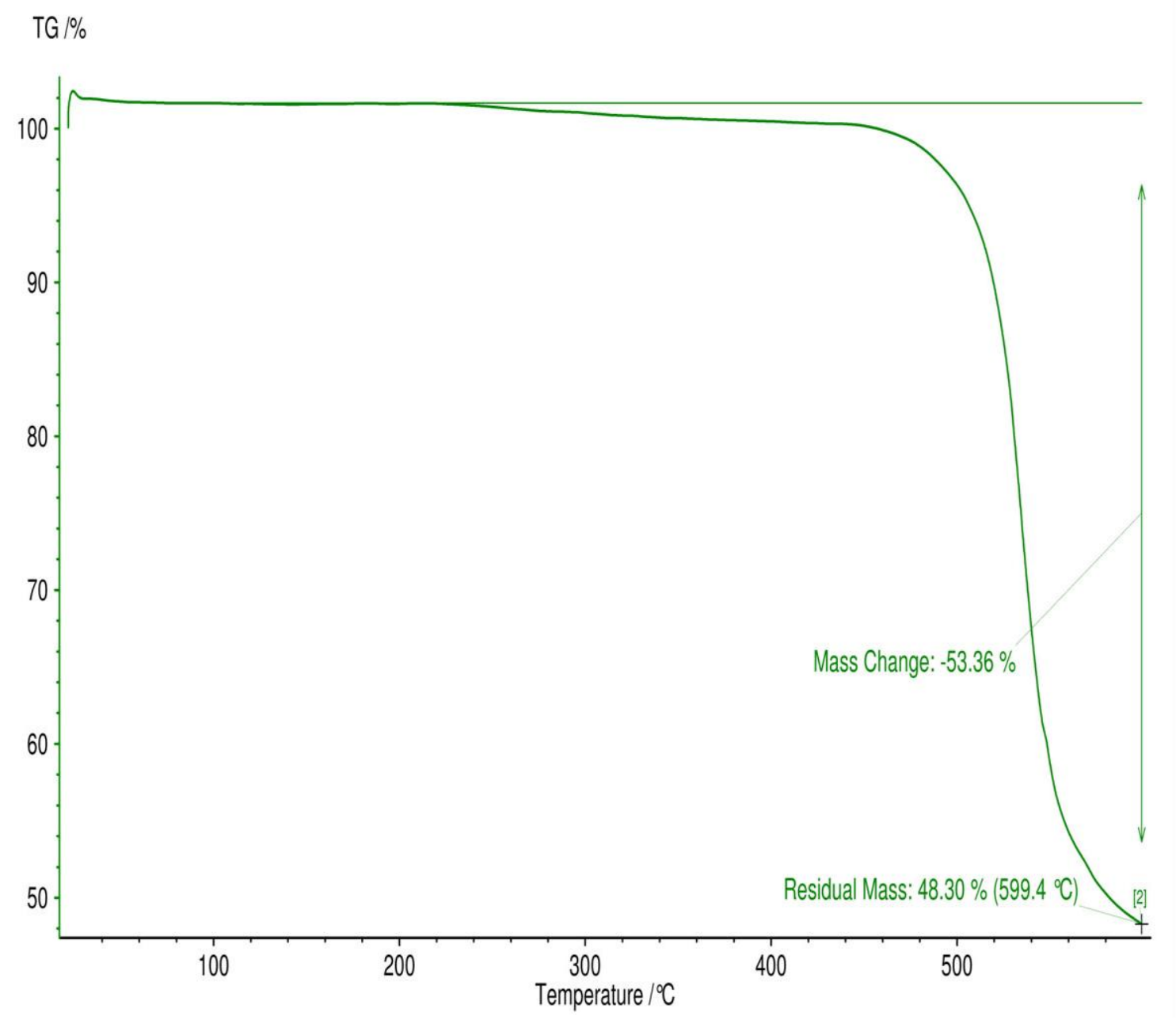

Figure 17. TGA of $\mathrm{PSu}-\mathrm{Co}_{2} \mathrm{SiO}_{4}$ nanocomposite 


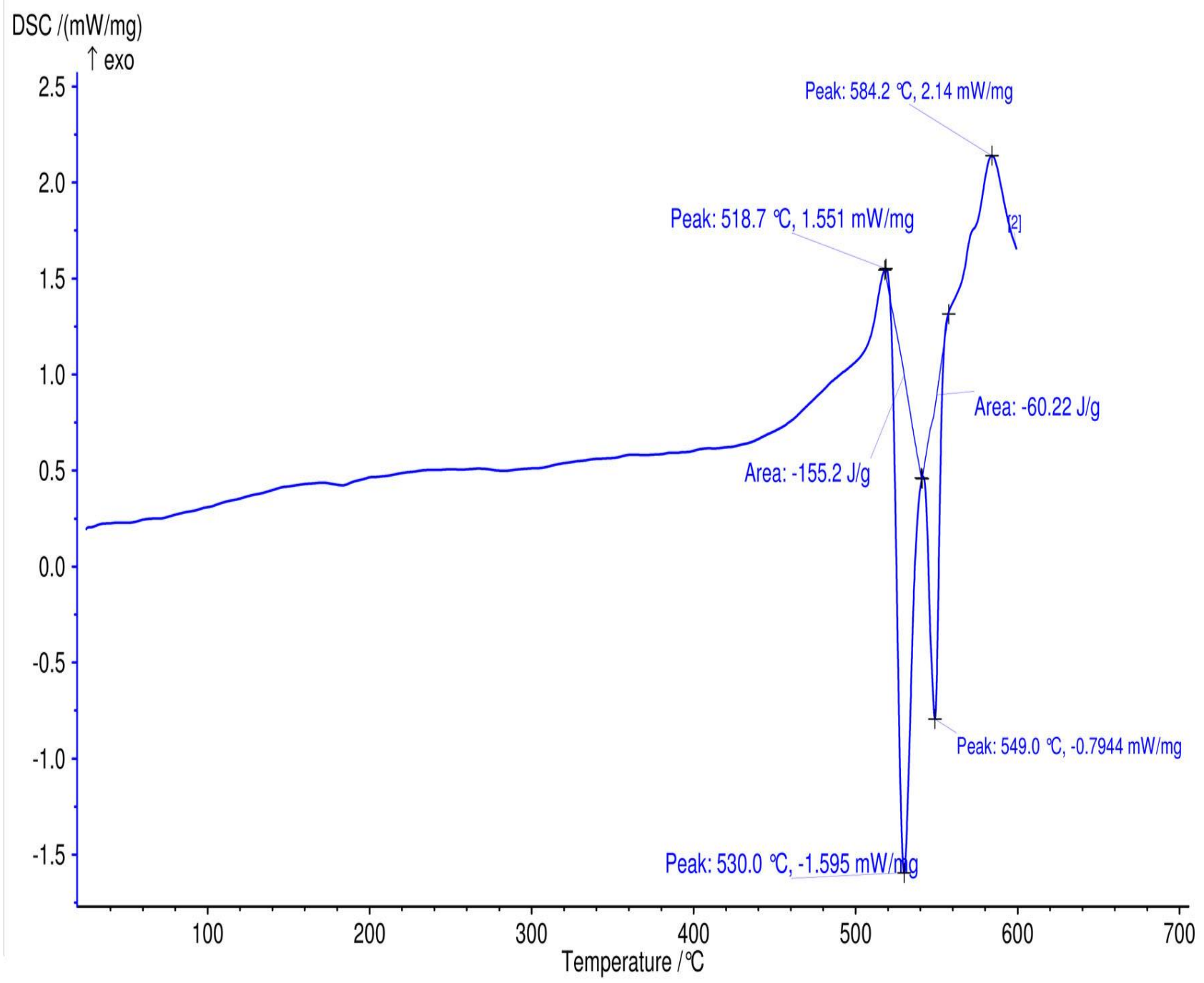

Figure 18. DSC analysis of $\mathrm{PSu}-\mathrm{Co}_{2} \mathrm{SiO}_{4}$ nanocomposite 

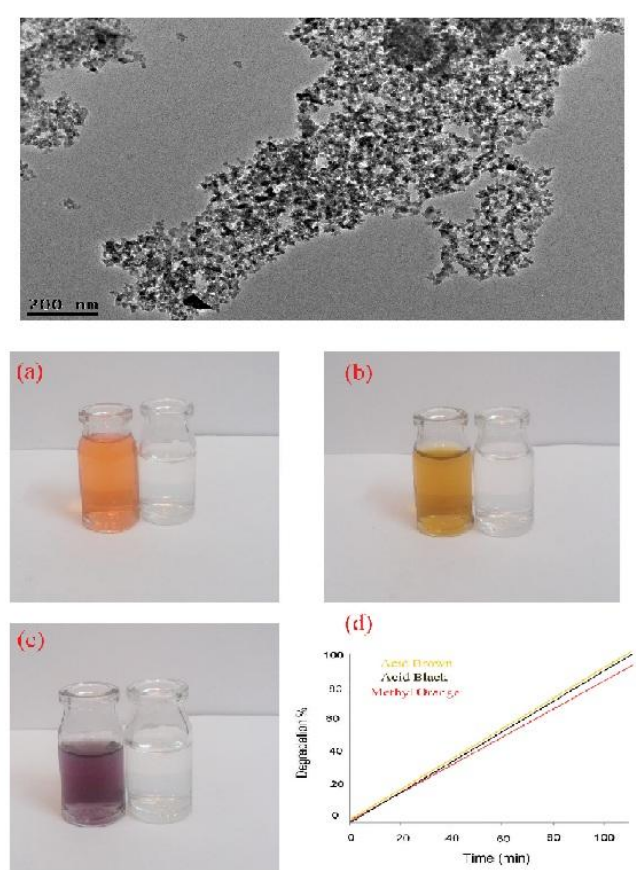